The Polish Journal of the Arts and Culture. New Series 13

(1/2021): 201-212 [REPORT]

DOI: 10.4467/24506249PJ.21.010.13737

\title{
An Examination of Non-Conventional Materials in Post-modern Nigerian Paintings
}

\section{Abodunrin JoHnson AdELANi}

Abodunrin Johnson Adelani is currently a Reader in the department of Fine and Applied Arts LAUTECH with vast research in the area of Nigerian Painting. He has several Publications, both locally and internationally. His scholarship has been in the area of painting and related issues in visual arts studies in Nigeria. He has been able to do the typology and classification of forms of painting in Nigeria and iconographical classification of painting in modern Nigeria. More so, his research adopted both qualitative and quantitative approaches to tenacity and socio-cultural issues in the use of styles, media, techniques, themes and subject matter of paintings in Nigerian art. This has aided the understanding of issues related to the practice and scholarship in Nigerian painting. His research efforts have provided inputs in the promotion of paintings and visual arts scholarship through contributing to the cognitive strength of paintings. His scholarly ideas in painting have been widely disseminated to the academic community of visual Arts both nationally and internationally.

E-MAIL: jaabodunrin@lautech.edu.ng 


\section{Introduction}

Postmodernism is a late $20^{\text {th }}$ century style and concept in arts, architecture, and criticism, which represents a departure from modernism and is characterised by the self-conscious use of earlier styles and conventions, mixing different artistic styles and media, and a general distrust of theories. The use of materials for painting in postmodern Nigeria has become so explosive that the direction is no longer comprehensible; this has made this study expedient. Mixed media in painting is a concept that was developed in the $20^{\text {th }}$ century when postmodern artists began to twist the traditional rules and is associated with each medium being used together. Painting with mixed media is a fun exploration of the many different ways traditional paint may be mixed with other media to create an exciting range of artwork. Mixed media painting forces the artist to use different art medium combined in a single painting. However, this technique was also common among artists of different periods to express both figurative and non-figurative art forms. It can take the form of collage which involves gluing objects to canvas or board along with some colour effects. Mixed media is really an open form that allows the artist an amazing degree of freedom in terms of technique and material.

In Nigeria, artists engage in the use of similar materials and techniques of application as their counterparts worldwide. They use imported materials such as oil tubes, palette knives, painting knives, linseed oil, turpentine, brushes, as well as a few materials that are locally improvised such as kerosene, rags, perforated tins, olive oil, and others to achieve good painting effects (Johnston 1976). Painting in $21^{\text {st }}$ century in Nigeria has taken on a new dimension with the exploration of materials and techniques including the adoption of multidimensional materials which are combined to form an aesthetically appealing composition. This has introduced uniqueness and distinct styles through the use of materials and techniques. This study examines various painting media combined with each other as well as with other materials which may seem unconventional. It also demonstrates how to use materials that are not normally associated with painting to create mixed media art. One of the strengths of painting with mixed media or unconventional materials is the sheer number of techniques it demonstrates, including painting, drawing, layering, collaging,texturizing, graffito, peeled paint effect, mono printing, frottage, rubbing, slicing, weaving and others (Getlin2002). Painting with unconventional materials in Nigeria encour- 
ages an artist to step out of the box, to move beyond the concept of simply applying paint to canvas and to try out some new things, explore novel techniques. The only possible challenge in using such unconventional materials for the purpose of painting is storage and preservation. Painting on an improperly prepared surface can result in an unstable support, leading to paint flaking. Proper technique and the choice of material will contribute to more stable and long-lasting experimentation.

\section{Close-up on the Materials}

Technically speaking, a painting is a two-dimensional art form which is made up of layers of pigments applied onto a surface. The surface on which the pigments are applied varies from stone to paper, wood, cloth, board, and canvas. As the surfaces differ so do the materials used to create the pigments. During the Paleolithic Age, earthy colours were used, followed by plant extracts and more recently synthetic colours (Gombrich 1966). The use of materials and the techniques of their application are very important in artistic practice and this has become paramount even in comparison to any form of detailing in a work of art (Johnston 1976). Artists need to master their chosen materials in order to use them in the most effective way. The right choice of material and technique of application facilitates the expression of uniqueness and professional expertise in practice. The "tradition" of using non-conventional materials and found materials in art goes back awhile, from Braque and Picasso's collages to Ducham's urinal (Khosrow 2009). The use of found objects has to transform the material into art.

In painting, certain materials have, over the years, been explored to achieve various expressive possibilities such as oil paint, acrylic, water colour paint, gouache paint, pastel etc. Paint is made of pigments - finely ground chemical or mineral powders, and a binder, a viscous liquid substance that helps the paint spread (Boddy-Evan 2015). Many popular pigments have remained unchanged for centuries and are still used today. But overtime, the binders changed, offering different qualities that appealed to artists. Another evolving element was the support, the surface on which the painting was created. Common supports include wood panel, stretched canvas, and paper. Postmodern artists use non-conventional materials for the expression of different subject matter. 


\section{Non-conventional Art Materials: an Overview}

Conventional materials are regular materials used for artistic practice. These materials are those familiar to everyone, irrespective of the art form. It is said all that non-conventional materials are the ones that are not traditionally used by artists. Nevertheless, they can have an enormous expressive potential. In postmodern art, exploration of forms and materials indicates a high level of creative abilities in the individual artist, thereby creating a new form of artistic landscape. Materials ranging from conventional and non-conventional are explored during numerous workshop and training in Nigeria. The participants of various workshops explored waste-to-wealth to create mixed media, for example such workshops as "Art is everywhere" established a pattern by sourcing materials that are not conventional for artistic practice (Odoh et al. 2014). Such art forms as painting, sculpture, textile and architecture have engaged in the use of non-conventional materials to achieve a different degree of innovation and inventions much admired by the general public.

However, painting involves the application of paint, pigment, colour or another medium to a surface (support base). The material is commonly applied to the base with a brush, but other implements, such as a knife, sponges, and air brushes, can be used (Johnston 1976). The traditional materials and other adapted materials are recently glued or attached to a surface to compliment the aesthetic of painting such as sculpted forms, beads, rugs, coloured buttons and other crafted materials. Artists in postmodern Nigeria have shifted from the traditional method of painting inherited from the Western world to what is termed individualistic. Individualism enables artists to do things in their own way without any interference. The artistic visions, goals and techniques of an individual artist can also be seen as innovative experiment that alters the artistic vision and, in this regard, their goals are not defined or precise. Artists in search of innovation and experimentation for identity use various styles, techniques and materials that are not traditionally meant for the purpose of painting, in order to explore forms.

Conceptual textile art comprises art made of fabrics, yarns/threads and fibers from animal and synthetic sources, using different techniques but now, postmodernism has encouraged exploration of materials that are not conventional such as beads, leather, wood, cardboard, plastic, polythene and other found objects (Dowuona-Hammond 2015). Sculpture materials are being sourced beyond the traditional materials - such as clay, cement, fiberglass, metal, stone, wood, plaster Paris, polymer clay, aluminum foil, and 
paper - to depict a different degree of artistic form. These materials are used independently or combined with other inspirational and non-conventional ones to achieve a high level of creative potential.

In architecture, the selection of material determines the cost and available facilities for production and processing in building construction. Industrialised materials such as polish, cement and steel are utilised in practically all civil engineering construction sites all over the world, even in countries where alternative and locally produced materials exist in abundance and are used to build in response to local climates (Khosrow 2009). There is an intense on-going search for non- polluting materials, which consume little energy in their production and application. The attention of researchers and industry has turned to non-conventional materials such as plant fibers (including bamboo), soil, stone, and lime for engineering application

\section{Methodology}

The painting samples were selected to exemplify various techniques, style, and media from different geographical and institutional backgrounds in Nigeria. A purposive sampling technique was used to select paintings with non-conventional materials in gallery, exhibition catalogues, and private collections in Nigeria, while descriptive survey and studio-based methods of research approach were adopted. Studio-based research was chosen because various materials interacted and were manipulated in a creative manner based on concepts that are likely to produce desired results. The paper examines case studies of twelve (12) new media artists with differing practices and artistic approaches. For each case study, semi-structured interviews with the artists were conducted in conjunction with visits to the artist's studio.

\section{Artists and Non-conventional Materials in Nigerian Painting}

In search of identity and exploratory tendencies in Nigerian art, artists embarked on the use of materials that are non-conventional in the practice of modern painting. These materials are used independently or combined with two or more materials as mixed media painting. The material experimentations represent the independent search for innovations and ideals undertaken by each artist, which can be varied. The study looked at the materials generally 
and classified them by nature and the orientation. They are assemblage materials, crafted materials and sculptural forms.

\section{Assemblage Materials in Painting}

This is an artistic composition made from scraps, junk, and odds and ends (paper, cloth, wood, stone, or metals). It is also an art form that involves the assembly and arrangement of unrelated objects, parts, and materials in a kind of sculptured collage. Many paintings in Nigeria belong to this category in terms of their application of mechanical tools, burnt plastic, jeans, fabric, leather and wood as materials for postmodern painting. These are used independently or in a combination of two or more to form an artistically appealing painting. For example, Best Ochigbo who has been eager to follow the trend of change has decided to contribute towards aesthetic development in our society, by exploring or experimenting with a technique of painting which he calls the "pyro technique" (Ochigbo 2009). This is a process in which heat is applied to plastic and wood to create a painting. The artist used discarded plastic materials to depict various forms and subject matter to the admiration of the audience (plate 1). The attempt has contributed to the environmental policies that facilitate a waste-to-wealth ideology.

It was not long after graduating from Yaba College of Technology that Kelani Abass moved from a conventional, stereotypical mode of expression to an intimate, highly independent style of painting. Kelani claimed that the style of gluing mechanical objects came from his experience in the printing industry as he was fascinated by the way machines operate as different parts to achieve a common goal. His use of mechanical materials to depict forms in his painting is exemplified in his Man and machine series (plate 2). His works in this direction go beyond easy realism; they are more in line with neo-expressionist experimentation. They are a mixture of abstract backgrounds with super imposed figurative elements and applied objects. The display between real and drawn mechanical elements is particularly successful.

Alex Nwokolo experimented with cloth and glued pieces of the newspapers, recently encapsulated in some spectacular mixed media works (plate 3). He makes use of the aforementioned materials and manipulates them for individual expressive and aesthetic possibilities. Preoccupied with surface quantities, he strives to achieve a texture form by pasting newspaper cuttings on canvas with glue. He proceeds to buff the pulpy canvas surface with sandpaper to a point where he can build forms in order to enhance his 


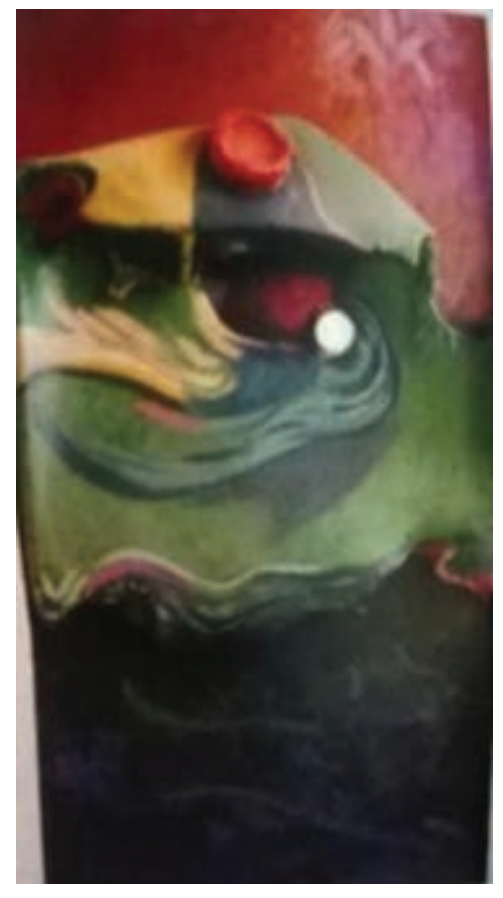

4 Plate 1. Best Ochigbo, Breastfeeding (2006). Burnt plastic and oil on board. Artist Archive

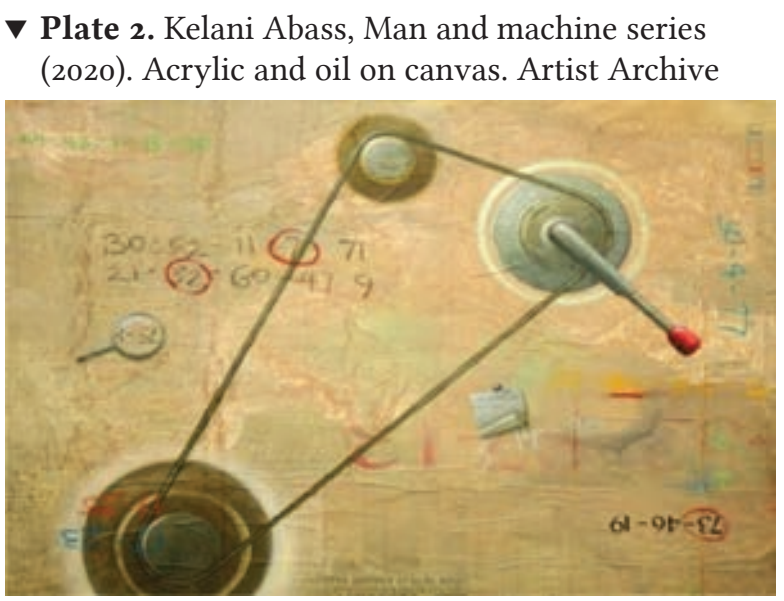

contemplated ideas. For instance, his painting is affixed almost seamlessly on the scraped surfaces before the actual myriads of images are depicted, which creates a peculiar textured effect.

Adegboyega Ismail who is a young and talented artist from Ladoke Akintola University, Ogbomoso also explored unconventional surfaces for painting by exploring an alternative support in the use of discarded vinyl records that he assembled as painting surface (plate 4), to depict the image of the juju music icon King Sunny Ade. He used the unconventional support to create dynamisms in the expression of painting.

\section{Crafted Materials in Painting}

Crafted material refers to any item that is made in some way, perhaps through basic crafting, but then serves its primary purpose in further formats. It may be possible to use the item in a minor capacity on its own, but its key application will be in the creation of further, better items. In Nigeria, crafted materials are explored to create a variety of ideas which often are combined with other materials to achieve a high level of creativity in painting. Artists 


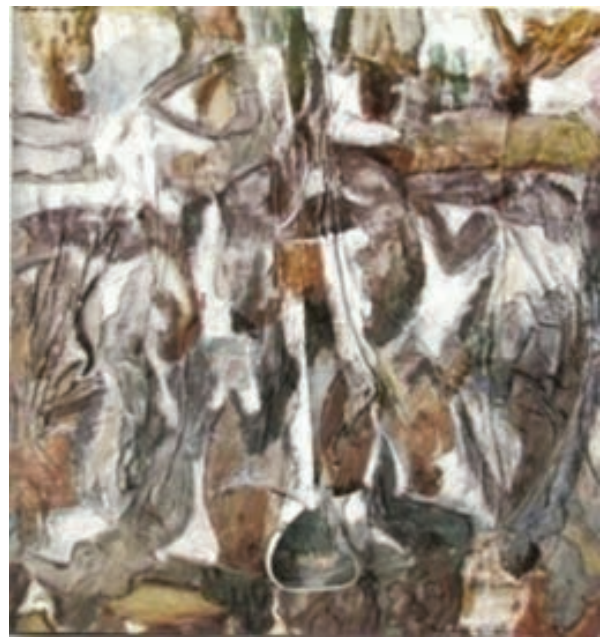

Plate 3. Alex Nwokolo, Untitled (2008). Oil on canvas. Musing: an exhibition of recent painting exhibition catalogue, 2009:4

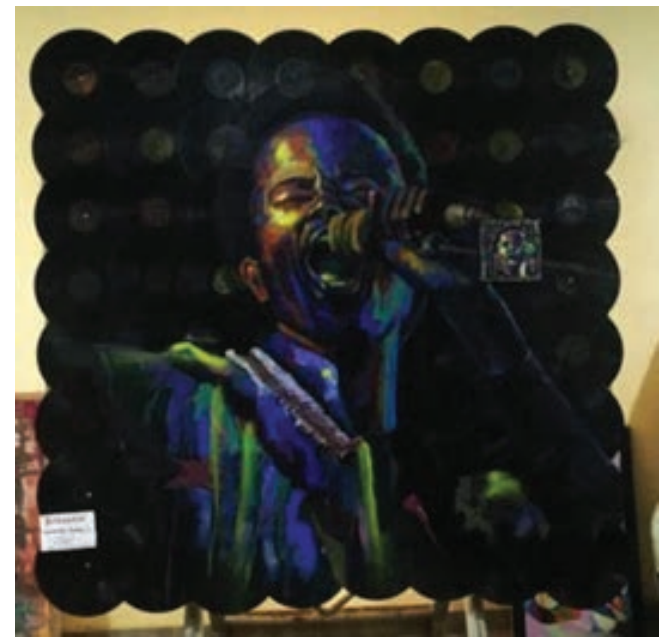

Plate 4. Adegboyega Ismail, King Sunny Ade (2018). Gramophone record plates. Lautech Art Gallery

use materials ranging from Ankara fabric, coloured buttons, beads, straw, wool, rugs and raffia mats to represent different subject matters in painting. For instance, Kolade Oshinowo is a naturalistic painter of note, who on many occasions used this masterly approach to influence many of his students at Yaba College of Technology and beyond. He graduated from Ahmadu Bello University, Zaria and specialised in painting. His recent innovative effort in using textile fabrics in creating explosive naturalistic paintings such as Sisi Ologe, (plate 5) and many others are exemplary in the recent explosive material techniques of his paintings. His recent innovations did not stray entirely from his classical tendencies, which he had been noted for. He definitely glides effortlessly between expressionism, naturalism, and realism. Heat tempts to portray figurative expressions on printed textile materials, which give his work a supernatural feeling to the admiration of the viewers.

Akinleye Azeez uses leather of different colours as an alternative to conventional paint to represent figurative expression in painting (plate 6). Leather crafting involves making leather in to craft objects using shaping techniques and appropriate selection of coloured leather to achieve good tonal value for the painting.

Okunade Olalekan's mat (raffia) painting is an exemplary innovation which requires gradual layering of oil colour on a highly texturised surface 


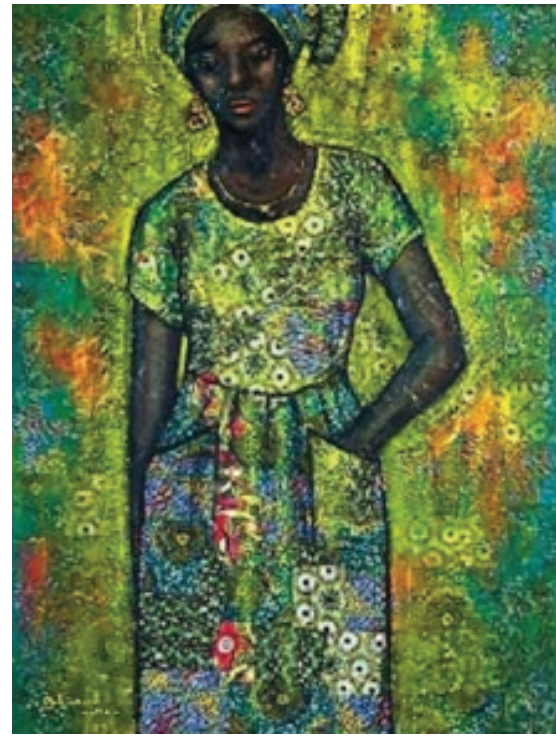

Plate 5. Kolade Oshinowo Sisi Ologe (2009). Ankara fabric and oil on board. Artist Archive

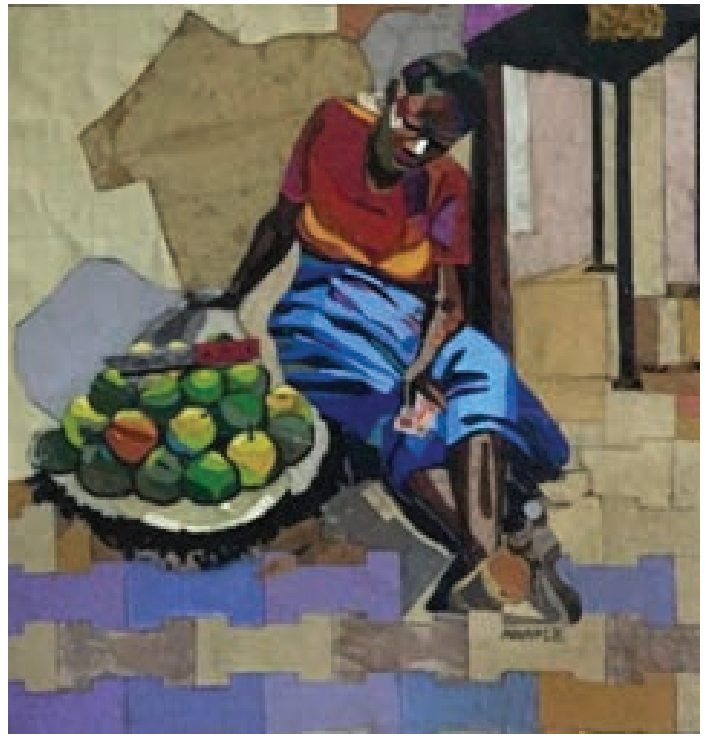

Plate 6. Akinloye Azeez, Fruit Seller (2018). Leather on board. Lautech Art Gallery

to achieve figurative expression (plate 7) while Agboola Jadesola uses buttons of different hues to portray the image of President Muhammadu Buhari, which is a painstaking and enduring image (plate 8).

\section{Sculptural Forms in Painting}

Sculptural forms for adaptation in postmodern painting involve sculptural materials combined with traditional painting materials to achieve high and low relief representations in art. An enormous variety of media may be used, including clay, wax, stone, metal, fabric, glass, wood, plaster, rubber, and other random found objects. These materials may be carved, modelled, moulded, cast, wrought, welded, sewn, assembled or otherwise shaped and combined with different expressions in mixed media painting. In Nigeria, the use of these non-conventional materials in painting has sometimes made painting and sculpture indistinguishable. Artists who have experimented with these materials recently include Ayo Akinyemi, Tobi Adekunle, Tomiwa Oyatomi and Cephas Ajibo

Ayo Akinyemi is an outstanding, experimental artist who has been experimenting with various possibilities and adaption of materials in painting. 


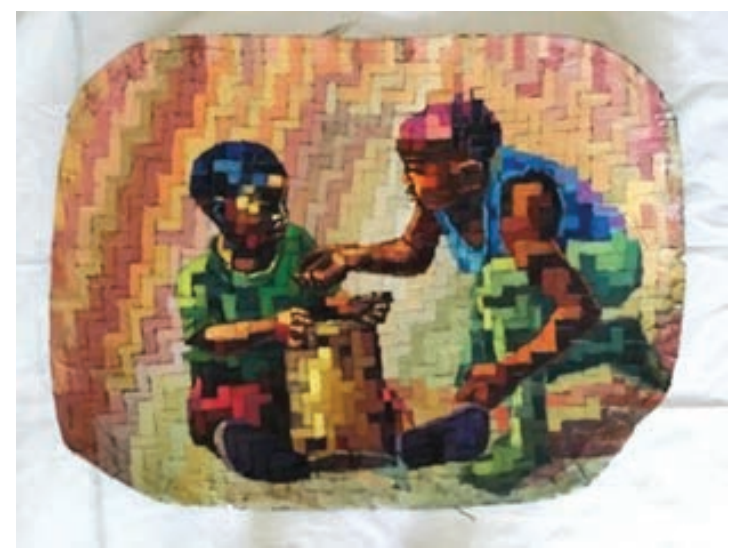

A Plate 7. Okunade Olamilekan, Toddler at play (2018). Oil on rafia mat. Artist Archive
Plate 8. Agboola Jadesola, Buhari (Sai Baba) (2018). Button and bead on board. Lautech Art Gallery

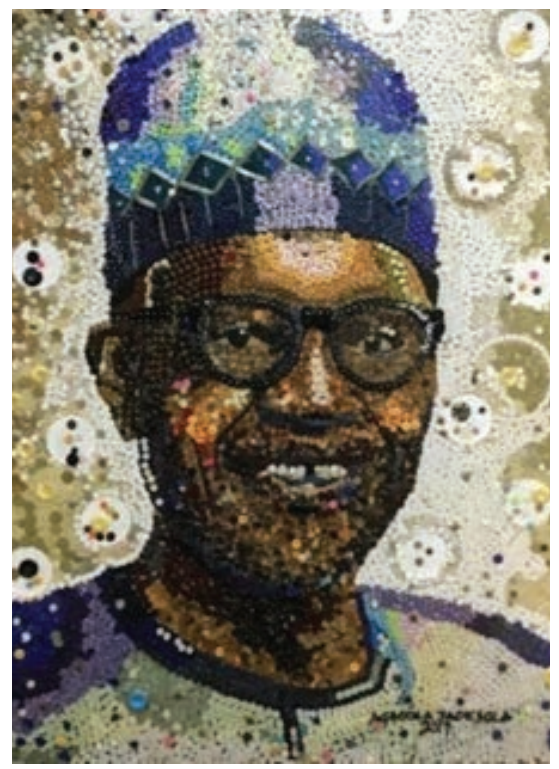

He is a graduate of painting at Ladoke Akintola University of Technology, Ogbomoso. His painting bursts with his passion to actualise his dreams in the use of non-traditional materials in painting such as glass painting. The act of painting on glass has always presented difficulties because of the texture of the surface. He used the support in a dynamic manner that it can be viewed directly unlike the reverse painting on the glass which is viewed by turning the glass over and looking through the glass at the image (plate 9).

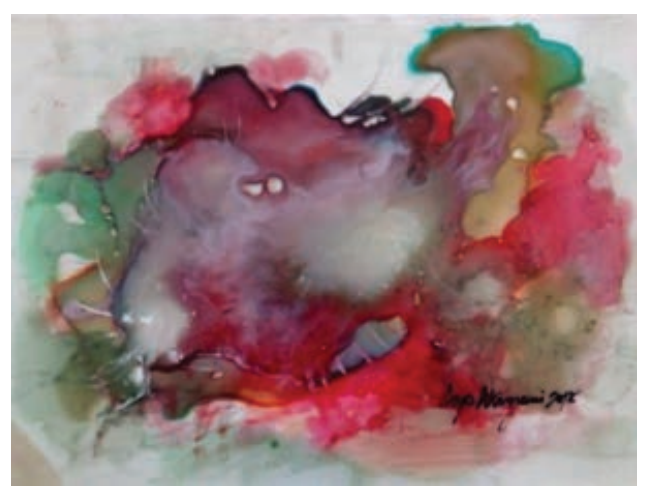

Plate 9. Ayo Akinyemi, Trancedence (2018). Glass colour on glass. Artist Archive.

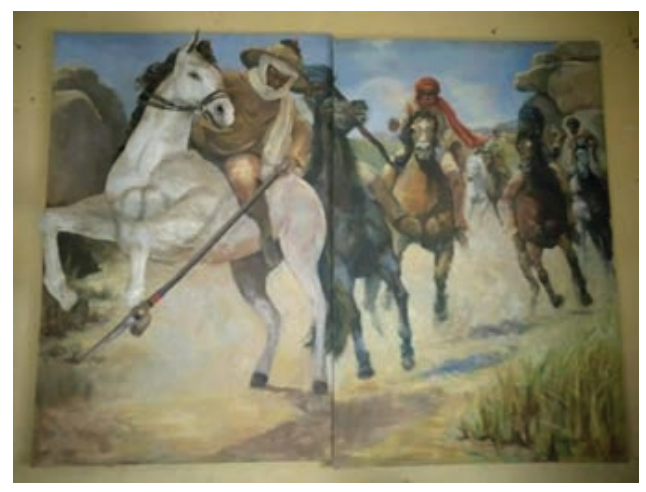

Plate 10. Tobi Adekunle, Untitled (2016). Fiber glass and oil on canvas. Lautech Art Gallery 


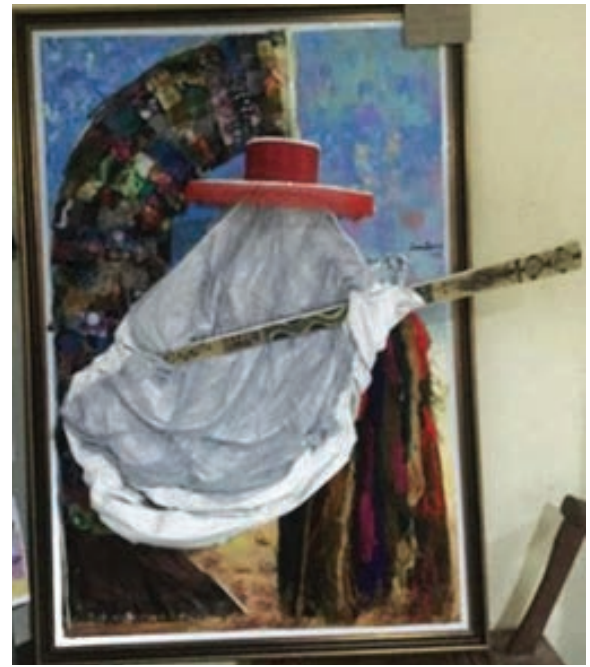

Plate 11. Tomiwa Oyatomi, Araorun, 2018. Fabric, cotton, oil on board. Lautech Art Gallery

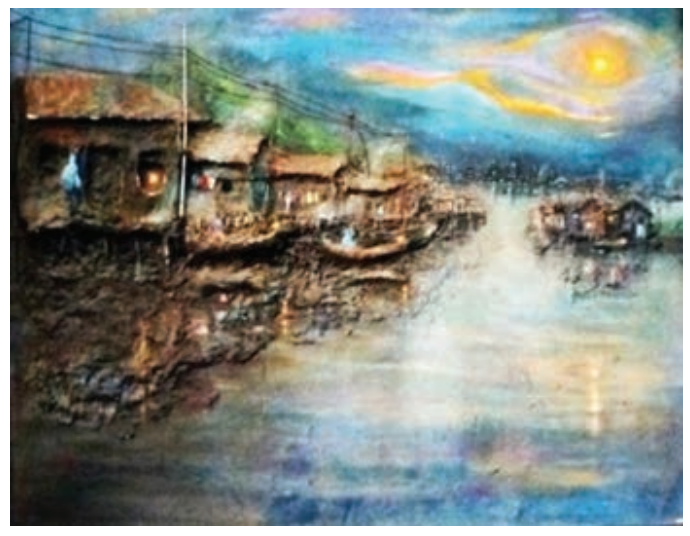

Plate 12. Cephas Ajibo, Makoko, 2016. Papermache, iron rod, and oil on board. Lautech Art Gallery

Tobi Adekunle is another graduate of painting with a special interest in combining sculpture and painting materials to create master pieces (plate 10). He mounted pre-sculpted forms with fiberglass materials and supported them with oil on canvas to suggest three-dimensional representations.

Tomiwa Oyatomi's painting explores another dimension of collage techniques involving pasting, gluing, tying various coloured materials in a dynamic manner to suggest a high relief form. In his painting entitled Ara Orun, three masquerades in Yoruba land were expressed with the dexterity and rhythmic performance for which they are noted (plate 11).

Cephas Ajibo uses papier-mâché and other found objects to build form before the actual colour expression (plate 12).

\section{Conclusion}

It has been established from this study that artists in Nigeria use different forms and discarded objects as materials for painting. Individualism and the search for identity have also contributed to the aggressive manipulation of non-conventional materials in painting. Paintings that use non-conventional materials represent rare artistic creativity - a phenomenon in the current trend of art work in Nigeria.The non-conventional materials used for painting are classified into three categories: namely, assemblage, crafted, and sculptural 
materials. These materials form definite solid shapes by creating different patterns in design for different types of painting. The uses of non-conventional art materials represent a highly artistic form of creativity that may be appealing to all art enthusiasts.

Note: The author expresses gratitude to all the Nigerian Artists who voluntary permitted me to use their artworks and illustrations for this study.

\section{Bibliography}

Boddy-Evan, Marion. 2015. Painting Techniques. Accessed February 22, 2018. http://painting. adout.com/od/artglossayp/g/definition-painting.htm.

Dowuona-Hammond, Doreen. 2015. Conventional and Non-conventional Materials in Conceptual Textile art. Postgraduate dissertation submitted to the College of Arts and Social Sciences, Ghana, Accessed June 12, 2021. http://ir.knust.edu.gh/bitstream/123456789/8234/1/Print\%20MFA\%20Thesis\%20Final.pdf.

Getlein, Mark. 2002. Living with Art. New York: McGraw - Higher Education.

Gombrich, Ernst Hans Josef. 1966. Studies in the Art of the Renaissance. London: Phaidon. Johnston, Richard Fleming. 1963. To Start You Painting. Macmillan.

Khosrow, Ghavami. 2009. Non-Conventional Materials and Technologies: Applications and Future Tendencies. Proceedings of the $11^{\text {th }}$ International Conference on Non-Conventional Materials and Technologies (NOCMAT) September 6-9, Bath UK.

Ochigbo, Best. 2009. Post Modernism Challenges and Assumptions in Best Ochigbo's Pyrotechnique in Painting. UUJH Sponsored by TETFund Project, University of Uyo, AkwaIbom State, Nigeria.

Odoh, en Uruchi et al. 2014. "Waste and Found Objects as Potent Creative Resources: A Review of the Art is Everywhere Project." International Journal of Humanities and Social Sciences 3, no 6: 1-4. 